\title{
Same, same but different: Perceptions of patients' online access to electronic health records among healthcare professionals
}

Sofie Wass and Vivian Vimarlund

The self-archived postprint version of this journal article is available at Linköping University Institutional Repository (DiVA):

http://urn.kb.se/resolve?urn=urn:nbn:se:liu:diva-157053

N.B.: When citing this work, cite the original publication.

This is a copy of the final, definitive version of this paper which has been published in:

Health Informatics Journal, 2018. (), pp..

Sofie Wass and Vivian Vimarlund, Same, same but different: Perceptions of patients' online access to electronic health records among healthcare professionals

Original publication available at:

https://doi.org/10.1177/1460458218779101

Copyright: SAGE PUBLICATIONS INC

https://uk.sagepub.com/ 
Research paper

\title{
Same, Same but Different: Experiences of Patients' Online Access to EHRs among Healthcare Professionals
}

\author{
Sofie Wass ${ }^{1}$ and Vivian Vimarlund ${ }^{2}$ \\ ${ }^{1}$ International Business School, Jönköping University, Sweden \\ ${ }^{2}$ International Business School, Jönköping University, Sweden, Linköping \\ University, Sweden
}

\begin{abstract}
In this study, we explore how healthcare professionals in primary care and outpatient clinics experience the outcomes of giving patients online access to their EHRs. The study was carried out as a case study and included a workshop, six interviews and a survey that was answered by 146 healthcare professionals. The results indicate that professionals working in primary care experience that an increase in information-sharing with patients can increase adherence, clarify important information to the patient and allow the patient to quality-control documented information. An interesting difference that was observed is that professionals at outpatient clinics seem less convinced about the benefits of PAEHRs. These negative experiences were related to how patients manage the information that they are given access to, and not concerns about increased work load. Although healthcare professionals have concerns, the PAEHR has not led to a change in documentation procedures among the majority of the professionals.
\end{abstract}

Keywords: electronic health records, healthcare service innovation and IT, organisational change and IT, patient-centeredness, work impact

Published in Health Informatics Journal

First Published June 7, 2018 Research Article

https://doi.org/10.1177/1460458218779101 


\section{INTRODUCTION}

During the last years, there has been an increasing focus on patient involvement and patient engagement through a more patient-centered approach ${ }^{1-4}$. Various strategies have been developed which emphasize the importance of patient-centered care and the new demands that are associated with this type of care ${ }^{5,6}$. A great deal of effort has been put into, for instance, digital services which potentially enhance information-sharing and communication with patients ${ }^{4,7}$. One example of this type of service is patient accessible electronic health records (PAEHR) which have the potential to improve healthcare delivery and health outcomes ${ }^{8,9}$ with benefits like improved recall and understanding of healthcare information $^{10,11}$, increased adherence ${ }^{12_{2}}$ and improved communication between patients and healthcare professionals ${ }^{10,11}$.

However, there exist divergent reports about the effects that PAEHRs have on healthcare professionals and their daily work ${ }^{8,9,13-19}$. A review identifies no negative effects for healthcare professionals who met with either outpatients or inpatients that could access the $\mathrm{EHR}^{8}$. These effects are also reflected in a study of a major project, where few physicians reported that they experienced an increased workload, because visits took longer time or they received more questions from their patients 9 . Other studies report on concerns, from both primary care physicians and specialist physicians, about patients becoming anxious or misinterpreting the content of the record ${ }^{13-17}$. However, there are studies that report that workload concerns, expressed prior to the system implementation, diminished when the service was actually put into practice ${ }^{9,18}$.

In general, studies that describe the benefits of PAEHR and the effects on healthcare professionals seem to focus on multi-payer or market-based financial systems ${ }^{9,12,20,21}$. In this study, we focus on the experiences of healthcare professionals who work in a publicly supported healthcare system and compare the experiences of professionals working in primary care and in outpatient clinics. We seek answers to the following research questions: How do healthcare professionals experience the outcomes of PAEHRs, in their daily work activities? Do healthcare professionals experience different outcomes depending on the unit that they work in?

\section{CASE DESCRIPTION}

In February 2015, the Region of Jönköping County gave all patients, aged 18 or older, online access to their EHRs. Through the national patient portal, patients can read their health-related information, including medical notes, diagnosis and vaccinations. The medical notes that are accessible on the system include information that was registered after July $1^{\text {st }}, 2014$. If a patient wants access to notes that were made before this date, they can request and receive these notes on paper. The decision to make the information available in this manner was made to give healthcare professionals the opportunity and the time necessary to modify the language that they used in the medical notes, before patients access the records online. Healthcare professionals have 14 days after documentation of the event to confirm and, if necessary, correct the medical notes before they become accessible to the patient. After 14 days, all notes are accessible, whether they have been confirmed or not. Healthcare professionals can use two keywords to keep information inaccessible to the patient. These keywords can be used to withhold suspected diagnoses which need further investigation before the final diagnosis is given to the patient, and notes about sensitive life-situations; for example, violence against women. At the time of the study, patients had been able to access the EHR for 15 months. 


\section{METHODS}

This study was performed as an explorative case study ${ }^{22}$ that included a workshop with six participants, six interviews and a survey answered by 146 healthcare professionals. First, we conducted a workshop to identify the expected benefits and drawbacks of the PAEHR. The workshop participants included the project manager, an eHealth strategist, a director of communication, two physicians and the system owner. During the workshop, we used a technique called "Pains and Gains" to structure the workshop ${ }^{23}$. The participants were asked to develop a "persona" ${ }^{24}$ who represented a healthcare professional whose patients could access the EHR. The persona was then used as a representation for healthcare professionals experiencing the introduction of the PAEHR and each participant was asked to indicate the expected benefits and drawbacks that the persona would face due to the PAEHR. The benefits and drawbacks were written on post-it notes and presented by each participant to the group. Finally, the group discussed the benefits and drawbacks that were identified and agreed on the most important outcomes.

During the second step of our research process, we interviewed four physicians, one nurse and one therapist (from both primary care and clinics) to test the validity of the results of the workshop. Additional information was gathered during the interviews, which complemented the previously identified benefits and drawbacks. The interviewees were recruited from a group of professionals that had answered a survey in an earlier study and had indicated their willingness to participate in further studies. The interviewees were asked to answer questions regarding their experienced benefits and drawbacks of the PAEHR and whether patient-professional communication had changed since patient access to the EHRs was granted. The interviews were recorded, subsequently transcribed and analyzed by means of inductive content analysis ${ }^{25}$. The first author reviewed the transcripts of the interviews and identified sentences that focused on the benefits and drawbacks of the PAEHR. These different sentences and paragraphs were then labeled with a code. By collating the codes that were related to each other in terms of their content, different themes were derived from the interviews.

After analyzing the interviews, an online survey was created which was based on insights that were gathered from the workshop and the interviews. The survey was sent out to healthcare professionals at six different sites in the region: three primary care units and three outpatient clinics. The respondents included healthcare professionals who were responsible for documenting information in the EHR, i.e. physicians, nurses, assistant nurses and occupational therapists. The sites were selected to enable a comparison between the experiences of healthcare professionals working at primary care units and at outpatient clinics. Participation was voluntary and anonymous and the individual answers were not accessible to any executives at the Region of Jönköping County. The distribution of the surveys lasted for three weeks in May 2016 and in November 2016 to extend the data gathering. Two reminders were sent out and, in total, 146 healthcare professionals completed the survey (total response rate $45 \%$ ): $75 \%$ of the respondents were women, age between 24 and 67, with a median working experience of 16 years or more. Twenty surveys, that did not include answers to all the questions, were excluded. The respondents answered along a 5-point Likert-scale whether they agreed or disagreed to different statements. We examined the results across a 3-level grade and comparisons between the respondents at primary care units and outpatient clinics were made. A summary of the data collection activities is presented in Figure 1. 


\begin{tabular}{|c|c|c|}
\hline $\begin{array}{l}\text { Step 1. Workshop that } \\
\text { aimed to identify } \\
\text { expected benefits and } \\
\text { drawbacks - } \\
6 \text { participants }\end{array}$ & $\begin{array}{l}\text { Step 2. Interviews that } \\
\text { aimed to validate and } \\
\text { complement the results of } \\
\text { the workshop - } \\
6 \text { interviewees }\end{array}$ & $\begin{array}{l}\text { Step 3. Survey that aimed to identify the } \\
\text { benefits and drawback of the PAEHR - } \\
3 \text { primary care units (response rate } 55 \% \text {, } \\
n=66), 3 \text { outpatient clinics (response rate } \\
35 \%, n=80 \text { ) }\end{array}$ \\
\hline
\end{tabular}

Figure 1: Overview of the data collection activities.

The quality of case studies can be judged by a number of criteria ${ }^{22}$. In the present study, constructs validity has been achieved through the use of multiple sources of evidence and by allowing respondents to review collected data. To increase reliability, we strove to be transparent about how the data was collected and we organized and structured the data into different categories.

\section{RESULTS}

The results are presented in three sections. First, we present the expected benefits and drawbacks that were identified during the workshop and then the experienced benefits and drawbacks that were identified during the interviews and in the survey.

\section{RESULTS FROM THE WORKSHOP}

The results from the workshop indicated that the participants expected the following benefits: enhanced information-sharing, the possibility of establishing mutual understanding between the patient and the care provider, increased patient involvement and a better prepared patient. The expected drawbacks included: healthcare professionals being expected to be more up-to-date about their patients' situations and healthcare professionals being unable to document desired information in the EHR. The participants of the workshop also mentioned the risk of patients misinterpreting and getting upset about the information that is recorded in the EHR.

\section{RESULTS FROM THE INTERVIEWS}

The interviewees noted a number of benefits and drawbacks with the PAEHR. The keythemes that emerged from the interviews are presented in Table 1 and described in more detail, with quotations from the interviewees, in the following section.

Table 1: Benefits and drawbacks identified from the interviews. ' $P$ ' represents physicians $\mathrm{P} 1, \mathrm{P} 2$, and so on. ' $\mathrm{N}$ ' represents the nurse and ' $\mathrm{T}$ ', the therapist.

\begin{tabular}{|c|c|c|c|}
\hline Benefits & Respondent & Drawbacks & Respondent \\
\hline Enhanced information access & $\mathrm{P} 1, \mathrm{P} 3, \mathrm{~N}$ & Exposed and vulnerable patients & $\mathrm{P} 1, \mathrm{~T}$ \\
\hline Improved understanding & $\mathrm{P} 1, \mathrm{P} 2, \mathrm{P} 4, \mathrm{~T}$ & $\begin{array}{l}\text { Negative impact on work } \\
\text { processes }\end{array}$ & P3, P4 \\
\hline $\begin{array}{l}\text { Increased patient involvement } \\
\text { Positive impact on work } \\
\text { processes }\end{array}$ & $\begin{array}{l}\mathrm{P} 1, \mathrm{P} 2, \mathrm{~T}, \mathrm{~N} \\
\mathrm{P} 1, \mathrm{P} 2, \mathrm{~N}\end{array}$ & Worries and misunderstandings & P2, P3, P4 \\
\hline
\end{tabular}

The PAEHR was viewed as an initiative that made information easier to access for the patient. The interviewees spoke about patients accessing the information where and whenever he/she wants. "...it can be positive for some patients, especially those who cannot take in all the information, then they can access and read it at home in peace and quiet." (P3) Several respondents mentioned improved understanding as a benefit for the 
patient. "If you have been to an appointment and met the doctor, to be able to log in and double-check that you have understood the doctor..." (T) They mentioned the possibility of accessing the EHR to repeat what was said, "It can be nerve-wracking to have a doctors" appointment, and you can have it as an extra memory." (P4) It was also described as a way to ensure that there was a mutual understanding of the situation, "... if you need to repeat [the information], then you can understand more of what we really had a mutual understanding about." (P1)

Respondents talked about patients who could get more active and involved in healthcare because of the PAEHR. One respondent said, "So I believe that it gets more transparent, and that we walk away from the hierarchal, patriarchal world even more. That you actually co-produce...I believe that, that is part of the person-centered care, that the patient gets more active in his or her own healthcare." (T) One physician spoke about educating the patient. "You have to give them the tools so that they really feel safe. It is very much about patient development and patient education." (P1) Another respondent hoped that the increase in information-sharing through the service would result in fewer phone calls. "When you can follow your case, then I think and hope that we can avoid a lot of unnecessary phone calls. People wonder what is happening and then they can actually find it on their own...A lot of questions are actually asked because people do not know." (P2) One respondent also mentioned the possibility of patients identifying and correcting inaccurate entries in the EHR. "One time we got a notice and then we corrected it. It was not my notes but a doctors' note and it feels really good. Because then you can remove incorrect information." (N) The type of language used to document in the EHR was also discussed. For instance, one interviewee said, "We have a working language just like any other craftsman or -woman, and that we must continue to use, but we also have to be pedagogical in that we can write a summary on what you call 'simple Swedish'." (P1)

Concerning drawbacks, two respondents mentioned the risk of other people who might force the patient to show them their EHR. This included issues related to abortion and domestic violence. "I see a risk if you are a young woman and have contacted us for an abortion for instance, and if your parents then force you to access your health record." (P1) The therapist mentioned domestic violence "In destructive relations, where you can be forced to show the information." (T) Some respondents were worried that the PAEHR might cause a further strain on the provision of healthcare in that it would result in more questions being asked by patients. One respondent explained that it was less timeconsuming to call patients instead of patients accessing the information online and then asking questions. "We are scared that it will result in much more work when they introduce test results and radiology, that it will be a lot of extra questions." (P4) The drawbacks of the PAEHR also included concerns about patients getting worried or misinterpreting information. One physician explained that there is sometimes a need to continue with a medical investigation before one informs the patient about their condition. "What I am worried about is that people might get hurt because they get a decision before I am able to find out...I might want to talk to colleagues." (P4) Another physician said, "... it is not that simple, and they cannot interpret it in the right way on their own. If you see a blood level on 13, what do you understand of that?" (P3)

\section{RESULTS FROM THE SURVEY}

More than $50 \%$ of the survey respondents reported the PAEHR was a 'good' or 'very good' initiative. When we compared the answers from respondents working in primary care units and outpatient clinics, the data showed that there were small differences between these two 
groups $(55 \%$ versus 53\%). However, the more detailed questions showed that the respondents working in primary care were more positive towards the use of the PAEHR in comparison to the respondents working in outpatient clinics.

Table 2: Healthcare professionals' experiences about benefits of the PAEHR.

\begin{tabular}{|c|c|c|c|c|}
\hline The service makes it easier to... & $\begin{array}{l}\text { Primary care } \\
\text { units/ } \\
\text { Outpatient clinics }\end{array}$ & $\begin{array}{l}\text { Agree or } \\
\text { somewhat } \\
\text { agree }\end{array}$ & $\begin{array}{l}\text { Neither } \\
\text { agree nor } \\
\text { disagree }\end{array}$ & $\begin{array}{l}\text { Disagree or } \\
\text { somewhat } \\
\text { disagree }\end{array}$ \\
\hline \multirow{2}{*}{$\begin{array}{l}\text { clarify what is important to the } \\
\text { patient }\end{array}$} & Primary & $50 \%(33)$ & $26 \%(17)$ & $24 \%$ \\
\hline & Outpatient & $26 \%(21)$ & $38 \%(30)$ & $36 \%$ (29) \\
\hline \multirow{2}{*}{$\begin{array}{l}\text { increase adherence to the advice I } \\
\text { provide the patient }\end{array}$} & Primary & $50 \%$ & $35 \%(23)$ & $15 \%(10)$ \\
\hline & Outpatient & $35 \%(28)$ & $35 \%(28)$ & $30 \%(24)$ \\
\hline \multirow{2}{*}{ communicate with the patient } & Primary & $36 \%(24)$ & $36 \%(24)$ & $27 \%(18)$ \\
\hline & Outpatient & $20 \%(16)$ & $39 \%(31)$ & $41 \%(33)$ \\
\hline
\end{tabular}

Half of the respondents working in primary care, 'agreed' or 'somewhat agreed' that the PAEHR made it easier to clarify what is important to the patient, while only $26 \%$ of the respondents from outpatient clinics experienced that the PAEHR contributes to the clarification of what is important to the patient. The same pattern can be observed with issues related to adherence; $50 \%$ of the respondents in primary care versus $35 \%$ of respondents in outpatient clinics 'agreed' or 'somewhat agreed' that patient access to the EHR contributed to increased adherence. $36 \%$ of the respondents in primary care experienced that it was easier to communicate with the patients, while $20 \%$ of the respondents in outpatient clinics 'agreed' or 'somewhat agreed'. In general, the results show that the respondents in the outpatient clinics were less positive to the PAEHR and they 'disagreed' or 'somewhat disagreed' to a larger extent on this point than respondents from primary care (Table 2 ).

Table 3: Healthcare professionals' experiences about benefits related to the patient.

\begin{tabular}{lllll}
\hline $\begin{array}{l}\text { The service has made the } \\
\text { patient... }\end{array}$ & $\begin{array}{l}\text { Primary care units/ } \\
\text { Outpatient clinics }\end{array}$ & $\begin{array}{l}\text { Agree or } \\
\text { somewhat } \\
\text { agree }\end{array}$ & $\begin{array}{l}\text { Neither agree } \\
\text { nor disagree }\end{array}$ & $\begin{array}{l}\text { Disagree or } \\
\text { somewhat } \\
\text { disagree }\end{array}$ \\
\hline $\begin{array}{l}\text { more involved in his/her } \\
\text { treatment and/or rehabilitation }\end{array}$ & Primary & $35 \%(23)$ & $44 \%(29)$ & $21 \%(14)$ \\
\hline $\begin{array}{l}\text { more prepared for an } \\
\text { appointment }\end{array}$ & Primary & $24 \%(19)$ & $55 \%(44)$ & $21 \%(17)$ \\
\hline $\begin{array}{l}\text { able to quality-control what I } \\
\text { document }\end{array}$ & Outpatient & $29 \%(19)$ & $49 \%(32)$ & $23 \%(15)$ \\
\hline
\end{tabular}

Slightly more respondents in primary care 'agreed' or 'somewhat agreed' that patient access had made the patient more involved in his or her treatment and more prepared. However, more respondents working in primary care units were positive to issues related to quality-control than the respondents working in outpatient units. $46 \%$ of the respondents in primary care versus $26 \%$ of the respondents in outpatient clinics 'agreed' or 'somewhat agreed' that patient access contributed to quality-control (Table 3 ).

Table 4: Healthcare professionals' experiences about drawbacks related to the patient.

\begin{tabular}{lllll}
\hline $\begin{array}{l}\text { The service has resulted in } \\
\text { that the patient... }\end{array}$ & $\begin{array}{l}\text { Primary care units/ } \\
\text { Outpatient clinics }\end{array}$ & $\begin{array}{l}\text { Agree or } \\
\text { somewhat } \\
\text { agree }\end{array}$ & $\begin{array}{l}\text { Neither agree } \\
\text { nor disagree }\end{array}$ & $\begin{array}{l}\text { Disagree or } \\
\text { somewhat } \\
\text { disagree }\end{array}$ \\
\hline $\begin{array}{l}\text { becomes upset about the } \\
\text { information that can be read }\end{array}$ & Primary & $26 \%(17)$ & $55 \%(36)$ & $20 \%(13)$ \\
\hline
\end{tabular}




\begin{tabular}{lllll}
\hline becomes worried about the & Primary & $36 \%(24)$ & $47 \%(31)$ & $17 \%(11)$ \\
information that can be read & Outpatient & $53 \%(42)$ & $35 \%(28)$ & $13 \%(10)$ \\
\hline misunderstands the information & Primary & $33 \%(22)$ & $47 \%(31)$ & $20 \%(13)$ \\
in the health record & Outpatient & $49 \%(39)$ & $38 \%(30)$ & $14 \%(11)$ \\
\hline
\end{tabular}

The table above shows that respondents working in outpatient clinics are more concerned about patients becoming upset, worried or misunderstanding information in the EHR. For instance, $45 \%$ of the respondents working in outpatient clinics 'agreed' or 'somewhat agreed' that the patient becomes upset, while only $26 \%$ of the respondents from primary care experienced patients becoming upset. A similar difference exists with respect to issues related to worries and misunderstandings; $53 \%$ of the respondents in outpatient clinics 'agreed' or 'somewhat agreed' that the patient becomes worried, versus $36 \%$ of the respondents working in primary care. Moreover, $49 \%$ of the respondents in outpatient clinics 'agreed' or 'somewhat agreed' that the patient misunderstands information in the health record, compared to $33 \%$ in primary care (Table 4 ).

Table 5: Healthcare professionals' experiences about drawbacks of the PAEHR.

\begin{tabular}{lllll}
\hline $\begin{array}{l}\text { The service has resulted in that } \\
\text { I... }\end{array}$ & $\begin{array}{l}\text { Primary care } \\
\text { units/ } \\
\text { Outpatient clinics }\end{array}$ & $\begin{array}{l}\text { Agree or } \\
\text { somewhat } \\
\text { agree }\end{array}$ & $\begin{array}{l}\text { Neither agree } \\
\text { nor disagree }\end{array}$ & $\begin{array}{l}\text { Disagree or } \\
\text { somewhat } \\
\text { disagree }\end{array}$ \\
\hline $\begin{array}{l}\text { use more time for the } \\
\text { appointment/phone call }\end{array}$ & Primary & $8 \%(5)$ & $38 \%(25)$ & $55 \%(36)$ \\
\hline $\begin{array}{l}\text { use more time to dictate/write } \\
\text { information }\end{array}$ & Outpatient & $10 \%(8)$ & $45 \%(36)$ & $45 \%(36)$ \\
\hline $\begin{array}{l}\text { cannot document what I want in } \\
\text { the medical notes }\end{array}$ & Primary & $23 \%(15)$ & $30 \%(20)$ & $47 \%(31)$ \\
\hline
\end{tabular}

The PAEHR seems to have little impact on the healthcare professionals' work and we observed only small differences between respondents working in primary care units and in outpatient clinics. $8 \%$ of the respondents working in primary care reported that they spend more time on appointments versus $10 \%$ of the respondents working in outpatient clinics. Similarly, 23\% (primary care) versus 24\% (outpatient clinics) of the respondents 'agreed' or 'somewhat agreed' that they spend more time on writing or dictating notes. $26 \%$ of those working in primary care units and $31 \%$ of the respondents working in outpatient clinics 'agreed' or 'somewhat agreed' that they cannot document everything what they want in the medical notes (Table 5).

Table 6: Experiences about the impact on documentation.

\begin{tabular}{lllll}
\hline Questions & $\begin{array}{l}\text { Primary care units/ } \\
\text { Outpatient clinics }\end{array}$ & Yes & No & $\begin{array}{l}\text { No, I did not know } \\
\text { that they existed }\end{array}$ \\
\hline $\begin{array}{l}\text { Have you changed the way } \\
\text { you document information? }\end{array}$ & Primary & $21 \%(14)$ & $79 \%(52)$ & - \\
\hline $\begin{array}{l}\text { Have you ever used the } \\
\text { keywords? }\end{array}$ & Primary & $35 \%(28)$ & $65 \%(52)$ & - \\
\hline
\end{tabular}

Around three-fourths of the respondents had not changed the way they document information in the record, $79 \%$ of those working in primary care and $65 \%$ of those working at outpatient clinics. With respect to the professionals who had changed the way they document information, they reported that they had made changes in the way they record specific symptoms related to mental illness, cancer, obesity, drug (ab-)use, and changes in the language that they use, including less 'provocative' language, abbreviations, and the use of Latin words. Only $5 \%$ of the respondents, from both groups, had used the special 
keywords to withhold information from patients. Respondents in outpatient clinics seem to be less aware of the use of the keywords to withhold information for the patient; $48 \%$ did not know that the keywords existed, compared to $29 \%$ of the respondents in primary care (Table 6).

\section{DISCUSSION}

In this study, we have explored how healthcare professionals experience the outcomes of PAEHRs, by comparing the experience of healthcare professionals working in primary care units and in outpatient clinics. The results of the study indicate that professionals working in primary care experience that an increase in sharing information with patients can be beneficial. The majority of them experience this as a way to increase adherence and to clarify important information to the patient. It is also seen as an opportunity for the patient to control what is documented in primary care notes. This is consistent with the experiences of patients who have described similar benefits, like increased adherence ${ }^{12}$ and enhanced understanding and recall of health information ${ }^{9-11}$. Healthcare professionals at outpatient clinics, on the other hand, seem less convinced about the benefits of the PAEHR. The survey results indicate that they are neither positive nor negative towards statements about increased adherence, clarification of information and quality-control.

In previous studies, results show that PAEHRs make patients feel more involved in their own care ${ }^{9-11,26}$. In this study, we also found indications for this during the workshop and in the interviews. However, the experiences reported in the survey, revealed that most healthcare professionals do not experience that their patients are more involved in his or her treatment or rehabilitation, and neither do they claim that their patients are more prepared for their appointments. Reports of an increased workload were rare in both groups and the majority of the healthcare professionals reported that there was no impact on the time that was used for setting up and attending to appointments or documenting information. Around one-fifth of the respondents reported that they used more time to dictate or write notes and that they had to be more up-to-date about their patients' health records. This finding is consistent with the study conducted by Delbanco, Walker ${ }^{9}$ which reported on little impact on the length of appointments or time used for documentation.

In line with previous studies ${ }^{14-17}$, the results from the workshop, the interviews and the survey reflect concerns about increased patient anxiety and misunderstandings of the information in the EHR. Interestingly, this was especially experienced by healthcare professionals in outpatient clinics, where approximately 50\% 'agreed' or 'somewhat agreed' to the statements about patient anxiety, misunderstandings and patients getting upset. It is interesting to note that half of the professionals working in outpatient clinics were not aware that it is possible to withhold information from the patient with respect to on-going diagnoses. Although healthcare professionals are concerned about patient anxiety and misunderstandings of the information in the EHR, the patient access to the EHR has not led to a change in documentation procedures among the majority of the healthcare professionals. In those cases that changes were made, specific symptoms, the use of abbreviations and Latin terms were items that were affected by the change. While outpatient clinics meet patients with severe or even life-threatening diseases, they also meet chronically ill patients who tend to be knowledgeable about their condition. In contrast to the concerns raised by the healthcare professionals, Rexhepi, Åhlfeldt ${ }^{27}$ found that cancer patients preferred to access their EHR even if some of the information 
contained therein was difficult to understand. They also note that this information did not generate anxiety or undue concern.

One limitation of our study is that we do not compare the experiences of different types of professionals. Despite this limitation, we believe that this study presents a relevant discussion of the experiences of healthcare professionals' working in both primary care units and outpatient clinics, and incorporates several different types of professionals and their experience of PAEHRs. Since case studies aim to reach analytical generalization ${ }^{25}$, our study provides knowledge about experiences in a specific context. It is thus of some importance to further investigate whether these findings can be replicated in other settings.

\section{CONCLUSION}

Healthcare organizations are moving towards increased information-sharing with patients through the application of various services. Previous studies indicate that patients wish to get online access to their healthcare information, ${ }^{10,28,29}$ but there are divergent reports on how healthcare professionals experience an increase in information sharing. Our study shows that healthcare professionals who work in primary care find benefits like increased adherence, clarification of important information and the possibility for patients to control what is documented. Professionals in outpatient clinics seem to be less convinced about the benefits of PAEHRs. The concerns include patients becoming upset, unduly worried and misinterpreting information. Nevertheless, patient access to the EHR has not led to a change in documentation procedures among the majority of the healthcare professionals. The PAEHR was expected to increase patient involvement and allow patients to be more prepared. However, the healthcare professionals did not experience this.

Since the concerns that were identified in this study are mainly about how patients will manage their access to the information and not the impact this may have on the healthcare professionals' work, it is important for managers to disseminate research findings with respect to patients' experiences, so as to ease the concerns of healthcare professionals. This seems to be especially important in outpatient clinics. In addition to this, a greater awareness about the possibility of withholding information for the patient about incomplete or tentative diagnoses, that need further investigation until otherwise confirmed, might limit the professionals' experience of being restricted in terms of what they document in the EHR.

Future research should be conducted on investigating why professionals in outpatient clinics and primary care units have different concerns about their patients accessing the EHR. It will be of interest to clarify whether this can be connected to organizational factors, questions from patients and the different practices of healthcare professionals.

\section{Funding}

This research received no specific grant from any funding agency in the public, commercial, or not-for-profit sectors. 


\section{REFERENCES}

1. Koch S. Improving quality of life through eHealth - the patient perspective. The 24th Medical Informatics in Europe Conference. Pisa, Italy2012, p. 25-9.

2. Barry MJ and Edgman-Levitan S. Shared Decision Making - The Pinnacle of Patient-Centered Care. New England Journal of Medicine. 2012; 366: 780-1.

3. Berwick DM, Nolan TW and Whittington J. The Triple Aim: Care, Health, And Cost. Health Affairs. 2008; 27: 759-69.

4. Dwamena F, Holmes-Rovner M, Gaulden CM, et al. Interventions for providers to promote a patient-centred approach in clinical consultations. Cochrane Database of Systematic Reviews. 2012.

5. HealthIT.gov. Meaningful Use Regulations. 2016.

6. European Commission. eHealth Action Plan 2012-2020 - Innovative healthcare for the 21 st century. Brussels2012, p. 1-14.

7. Tang C, Lorenzi N, Harle CA, Zhou X and Chen Y. Interactive systems for patientcentered care to enhance patient engagement. Journal of the American Medical Informatics Association. 2016; 23: 2-4.

8. Ross SE and Lin C-T. The Effects of Promoting Patient Access to Medical Records: A Review. Journal of the American Medical Informatics Association. 2003; 10: 12938.

9. Delbanco T, Walker J, Bell SK, et al. Inviting Patients to Read Their Doctors' Notes: A Quasi-experimental Study and a Look Ahead. Annals of internal medicine. 2012; 157: 461-70.

10. Woods SS, Schwartz E, Tuepker A, et al. Patient Experiences With Full Electronic Access to Health Records and Clinical Notes Through the My HealtheVet Personal Health Record Pilot: Qualitative Study. J Med Internet Res. 2013; 15: e65.

11. Esch T, Mejilla R, Anselmo M, Podtschaske B, Delbanco T and Walker J. Engaging patients through open notes: an evaluation using mixed methods. BMJ Open. 2016; 6: e010034.

12. Wright E, Darer J, Tang X, et al. Sharing Physician Notes Through an Electronic Portal is Associated With Improved Medication Adherence: Quasi-Experimental Study. Journal of Medical Internet Research. 2015; 17: e226.

13. Prey JE, Restaino S and Vawdrey DK. Providing Hospital Patients with Access to Their Medical Records. AMIA Annual Symposium Proceedings. American Medical Informatics Association, 2014, p. 1884-93.

14. Ross SE, Todd J, Moore LA, Beaty BL, Wittevrongel L and Lin C-T. Expectations of Patients and Physicians Regarding Patient-Accessible Medical Records. J Med Internet Res. 2005; 7: e13.

15. Johnson AJ, Frankel RM, Williams LS, Glover S and Easterling D. Patient Access to Radiology Reports: What Do Physicians Think? Journal of the American College of Radiology. 2010; 7: 281-9.

16. Grünloh C, Cajander $\AA$ and Myreteg G. "The Record is Our Work Tool!"Physicians' Framing of a Patient Portal in Sweden. J Med Internet Res. 2016; 18: e167.

17. de Lusignan S, Mold F, Sheikh A, et al. Patients' online access to their electronic health records and linked online services: a systematic interpretative review. $B M J$ Open. 2014; 4: 1-11.

18. Allander $\mathrm{T}$ and Scandurra I. Experiences of Healthcare Professionals to the Introduction in Sweden of a Public eHealth Service: Patients' Online Access to their Electronic Health Records. MEDINFO. Sao Paulo, Brazil2015, p. 153-7. 
19. Oster NV, Jackson SL, Dhanireddy S, et al. Patient Access to Online Visit Notes: Perceptions of Doctors and Patients at an Urban HIV/AIDS Clinic. Journal of the International Association of Providers of AIDS Care (JIAPAC). 2015; 14: 306-12.

20. Vodicka E, Mejilla R, Leveille SG, et al. Online Access to Doctors' Notes: Patient Concerns About Privacy. J Med Internet Res. 2013; 15: e208.

21. Mafi JN, Mejilla R, Feldman H, et al. Patients learning to read their doctors' notes: the importance of reminders. Journal of the American Medical Informatics Association. 2016.

22. Yin RK. Case Study Research: Design and Methods. 5th ed. Thousand Oaks, California: Sage, 2014.

23. Gray D, Brown S and Macanufo J. Gamestorming : a playbook for innovators, rulebreakers, and changemakers. Sebastopol, CA: O'Reilly, 2010.

24. Cooper A. The inmates are running the asylum. Indianapolis, Ind.: Sams/Macmillan, 1999.

25. Graneheim UH and Lundman B. Qualitative content analysis in nursing research: concepts, procedures and measures to achieve trustworthiness. Nurse Education Today. 2004; 24: 105-12.

26. Wass S, Vimarlund V and Ros A. Exploring patients' perceptions of accessing electronic health records: Innovation in healthcare. Health Informatics Journal. 2017; 0: 1460458217704258 .

27. Rexhepi H, Åhlfeldt R-M, Cajander $\AA$ and Huvila I. Cancer patients' attitudes and experiences of online access to their electronic medical records: A qualitative study. Health Informatics Journal. 2016: 1-10.

28. Nazi KM, Hogan TP, McInnes DK, Woods SS and Graham G. Evaluating Patient Access to Electronic Health Records: Results From a Survey of Veterans. Medical Care. 2013; 51: S52-S6.

29. Baer D. Patient-Physician E-Mail Communication: The Kaiser Permanente Experience. Journal of Oncology Practice. 2011; 7: 230-3. 